\title{
Delayed effects of single neonatal subcutaneous exposure of low-dose 17a-ethynylestradiol on reproductive function in female rats
}

\author{
Mariko Shiorta', Jun Kawashima'1, Tomohiro Nakamura'1,Yuko Ogawa'1, Junichi Kamiie², \\ Kyohei Yasuno ${ }^{3}$, Kinji Shirota ${ }^{2,3}$ and Midori Yoshida ${ }^{4}$ \\ ${ }^{1}$ Laboratory of Comparative Toxicology, School of Veterinary Medicine, Azabu University, \\ 1-17-71 Fuchinobe, Chuo-ku, Sagamihara, Kanagawa 252-5201, Japan \\ ${ }^{2}$ Laboratory of Veterinary Pathology, School of Veterinary Medicine, Azabu University, \\ 1-17-71 Fuchinobe, Chuo-ku, Sagamihara, Kanagawa 252-5201, Japan \\ ${ }^{3}$ Research Institute of Biosciences, Azabu University, 1-17-71 Fuchinobe, Chuo-ku, Sagamihara, \\ Kanagawa 252-5201, Japan \\ ${ }^{4}$ Division of Pathology, National Institute of Health Sciences, 1-18-1 Kamiyoga, \\ Setagaya-ku, Tokyou 158-8501, Japan
}

(Received February 20, 2012; Accepted April 12, 2012)

\begin{abstract}
Delayed effects of exposure to small amounts of estrogenic compounds during the critical period of brain sexual differentiation were investigated by subcutaneous treatment of female SpragueDawley rats with 0 (vehicle control), $0.08,0.4$, or $2 \mu \mathrm{g} / \mathrm{kg}$ of $17 \alpha$-ethynylestradiol (EE) on postnatal day (PND) 1. The treatment did not affect growth and development of the treated animals, and the timings of vaginal opening were similar between the EE-treated and control groups. The animals were periodically examined for the estrous cycle from postnatal week (PNW) 8-9 to PNW 32-33. Patterns of the estrous cycle were similar among the groups until PNW 17. None of the control animals showed persistent estrus until PNW 33. The animals treated with $0.4 \mu \mathrm{g} / \mathrm{kg}$ or more EE showed persistent estrus from PNW 20. The alteration was reflected in the number of days judged as proestrus or estrus, and was found to gradually increase in the EE-treated groups. At necropsy on PNW 32-33, ovulation was not confirmed in most EE-treated animals, even on the day of estrus. In addition, sporadic milk accumulations were observed in the mammary gland of the EE-treated animals. Histological evaluation revealed cystic follicle formation in the EE-treated ovaries and also revealed hyperplasia of mammary glands. Furthermore, ovaries from the animals showing persistent estrus lacked corpus luteum, indicating long-term anovulation. These results clearly show that single exposure to EE during the critical period of brain sexual differentiation can exert effects on reproductive functions at a later period in rats.
\end{abstract}

Key words: Delayed effect, Ethynylestradiol, Critical period, Brain sexual differentiation, Estrous cycle, Estrogenic compounds

\section{INTRODUCTION}

During critical periods of morphogenesis and functional differentiation, animals are substantially sensitive to physiologically active xenobiotics. There are concerns that exposure to such chemicals during these critical periods causes profound adverse effects on exposed animals and humans. In rodents, such as rats and mice, the perinatal period is critical for brain sexual differentiation, and de novo synthesized estradiol in the brain by aromatization of testis-derived testosterone is a key signal for masculinization of the male brain. Because estradiol can also masculinize the female brain, exposure of the female brain to aromatizable testosterone or estrogenic compounds, such as synthetic estrogens, xenoestrogens, and phytoestrogens, causes masculinization of female neonates and loses cyclic revolution of estrus after puberty (reviewed in Gore, 2008).

Correspondence: Mariko Shiorta (E-mail: m-shirota@azabu-u.ac.jp) 
Although recent studies revealed molecular alterations in the brain after perinatal exposure to estrogenic compounds (Monje et al., 2010; García-Galliano et al., 2012), studies on the delayed effects of such compounds on development of reproductive function are limited to those by repeated administration during the neonatal period or by transgenerational administration. Briefly, $o, p$ 'dichlorodiphenyltrichloroethane (DDT), one of isomers of DDT, induces persistent vaginal estrus in rats when administered subcutaneously during PND 2-4 at dose levels of $0.1 \mathrm{mg}$ /animal or more (Gellert et al., 1974). Bisphnol-A (BPA), a monomer used in polycarbonate manufacture, has been extensively studied for its estrogenic properties (reviewed in Vandenberg et al., 2009), and has been found to induce persistent vaginal estrus in rats 15 weeks after the day of vaginal opening when administered subcutaneously at a dose level of $50 \mu \mathrm{g} / \mathrm{kg} \mathrm{BW}$ during PND 0-3 (Adewale et al., 2009). Similarly, BPA alters the estrous cycle of female rats at PND 100 when administered at a dose level of 0.05 or $20 \mathrm{mg} / \mathrm{kg} \mathrm{BW}$ during PND 1-7 (Monje et al., 2010). Methoxychlor is an organochlorine pesticide, and its injection increases irregular estrous cycle when administered to dams from gestational day 19 to PND 7 at a dose level of $100 \mathrm{mg} / \mathrm{kg} \mathrm{BW}$ (Armenti et al., 2008).

In the present study, we therefore evaluated delayed effects of a single low-dose exposure to estrogenic compounds during the critical period of brain sexual differentiation using EE as a model compound. EE is a synthetic estrogen that has been widely used as a constituent of contraceptive formulations. Because EE is orally active, it is used not only for medical purposes but also as a positive control in estrogenic potency studies such as the uterotropic bioassay in the Organization for Economic Co-operation and Development (OECD) test guidelines (Kanno et al., 2001, 2003; Owens and Koëter, 2003; Kim et al., 2005). The present study involving single administration of EE to neonatal female rats might help to estimate delayed effects of chemical substances showing estrogenic potency at various degrees.

\section{MATERIALS AND METHODS}

\section{Chemicals}

EE (CAS \#57-53-6; purity 99\%; Sigma-Aldrich Japan, Tokyo, Japan) was dissolved in ethanol (Wako Pure Chemical Industries, Osaka, Japan) at a concentration of $100 \mathrm{mg} / \mathrm{ml}$, and then the solution was diluted with corn oil (Wako Pure Chemical Industries) to formulate EE to a constant volume of $1 \mathrm{ml} / \mathrm{kg}$.

\section{Animals and housing}

Animal experimental procedures were approved by the Committee of Animal Experiment in the Azabu University. Pregnant Sprague-Dawley rats $[\mathrm{Crl}: \mathrm{CD}(\mathrm{SD})$ IGS] were purchased from Charles-River Japan, (Kanagawa, Japan). They were maintained in an animal facility under controlled conditions (lights on 08:00$20: 00 ; 21 \pm 1{ }^{\circ} \mathrm{C} ; 50 \%-60 \%$ humidity) in plastic cages with bedding materials (Sunflake; Oriental Kobo, Tokyo, Japan), pellet chow (CE-2; Clea Japan Inc., Tokyo, Japan), and water (tap water; supplied by Sagamihara City, Kanagawa, Japan) ad libitum.

\section{Experimental design}

The animals were daily checked for spontaneous delivery of fetuses. The day when delivery was confirmed was designated as postnatal day (PND) 0 of the pups. The pups were collected and assigned to treatment groups on PND 1. The pups in various treatment groups were identified using tattoos and placed under the same dams at eight pups per dam. If the number of treated pups was less than eight, untreated male pups were included to adjust the litter size to eight. In the present study, eight foster dams nursed four to seven female pups comprising one or two pups of each treatment group.

The animals were injected subcutaneously using a microsyringe (80401, Hamilton, NV, USA) on PND 1 with $0.08,0.4$, or $2 \mu \mathrm{g} / \mathrm{kg}$ EE or with $1 \mathrm{ml} / \mathrm{kg}$ corn oil (vehicle control). BW of the pups was measured on PND 1, weekly from PND 7, and on the day of necropsy. During the nursing period, the age at eye opening was determined as an index of physical development. The pups were weaned on PND 21 and examined for vaginal opening from PND 28. BW of the rats showing vaginal opening was measured. Estrous cycles were determined by vaginal cytology for two weeks at two-week intervals from postnatal week (PNW) 8-33. Estrous cycles were categorized as regular cycle (4-5 day cycle), persistent estrus (no consecutive days judged as diestrus or metestrus), and irregular cycle (neither regular cycle nor persistent estrus). In addition, the number of days judged as estrus or proestrus and those judged as diestrus or metestrus were calculated for each period.

Necropsy was performed during PNW 33-34 on the day of estrus if possible. The animals were euthanized under sodium pentobarbital anesthesia (Somnopentyl; Schering-Plough Animal Health, Osaka, Japan) by bleeding from the abdominal aorta. The pituitary gland, mammary gland, and major thoracic and abdominal organs were dissected, then, the ovaries, uterus, thymus, liver, kidneys and adrenal glands were weighed. The ova- 
Delayed effects of single neonatal injection of $17 \alpha$-ethynylestradiol

ries were fixed in Bouin's solution, and mammary glands were fixed in phosphate-buffered $10 \%$ formalin. Oviducts were collected to determine ovulation using Burdick and Whitney's method (Burdick and Whitney, 1941). Blood was centrifuged at 2,500 rpm for $25 \mathrm{~min}$ at $4^{\circ} \mathrm{C}$, and serum was stored at $-50^{\circ} \mathrm{C}$ for further analyses. The fixed ovaries were embedded in paraffin wax according to standard procedures. The specimens were cut serially into sections of $5 \mu \mathrm{m}$ in thickness and stained with hematoxylin and eosin. The fixed mammary glands were also embedded in paraffin wax by the same method, and were cut into sections of $5 \mu \mathrm{m}$ in thickness and stained with hematoxylin and eosin.

\section{Statistical analysis}

Statistical analysis was performed using JMP Statistical Analysis Software (SAS Institute, Cary, NC, USA). All data were analyzed using one-way analysis of variance (ANOVA). Differences between the control and EEtreated groups were analyzed by Dunnett's test. A $P$-value $<0.05$ was considered statistically significant.

\section{RESULTS}

\section{Effects of EE on growth and puberty}

The mean BW ( \pm standard error of the mean, S.E.M.) on PND 1, the day of administration, in the $0,0.08,0.4$, and $2 \mu \mathrm{g} / \mathrm{kg}$ EE-treated groups was $7.0( \pm 0.3), 7.4( \pm$ $0.3), 7.5( \pm 0.3)$, and $7.4( \pm 0.3)$, respectively, and the mean dose of EE per animal in these groups was calculated to be $0,0.59,3.00$, and $14.8 \mathrm{ng}$, respectively. As shown Fig. 1, there was no significant difference in the growth of animals among the groups, and other general abnormalities related to EE-treatment were not observed any group (data not shown). The timings of eye opening and vaginal opening of the treated animals were not significantly different between the EE-treated and control groups (Table 1).

\section{Effects of EE on the estrous cycle}

To determine if EE exposure had any effect on sexual development, we assessed pattern of the estrous cycle (Fig. 2) and the numbers of estrous cycles and days judged as estrus or proestrus (estrous/proestrous days) for each observation period (Table 2 ). In addition, the proportions of estrous/proestrous days and those judged as diestrus or metestrus (diestrous/metestrus days) during each observation period are illustrated in Fig. 3. In the control group, the numbers of estrous cycles and estrous/proestrous days for each observation period did not vary significantly during PNW 8-9 and rest of the periods, and no animal showed persistent estrus until PNW 33. In the EE-treated groups, the parameters were not significantly differ-

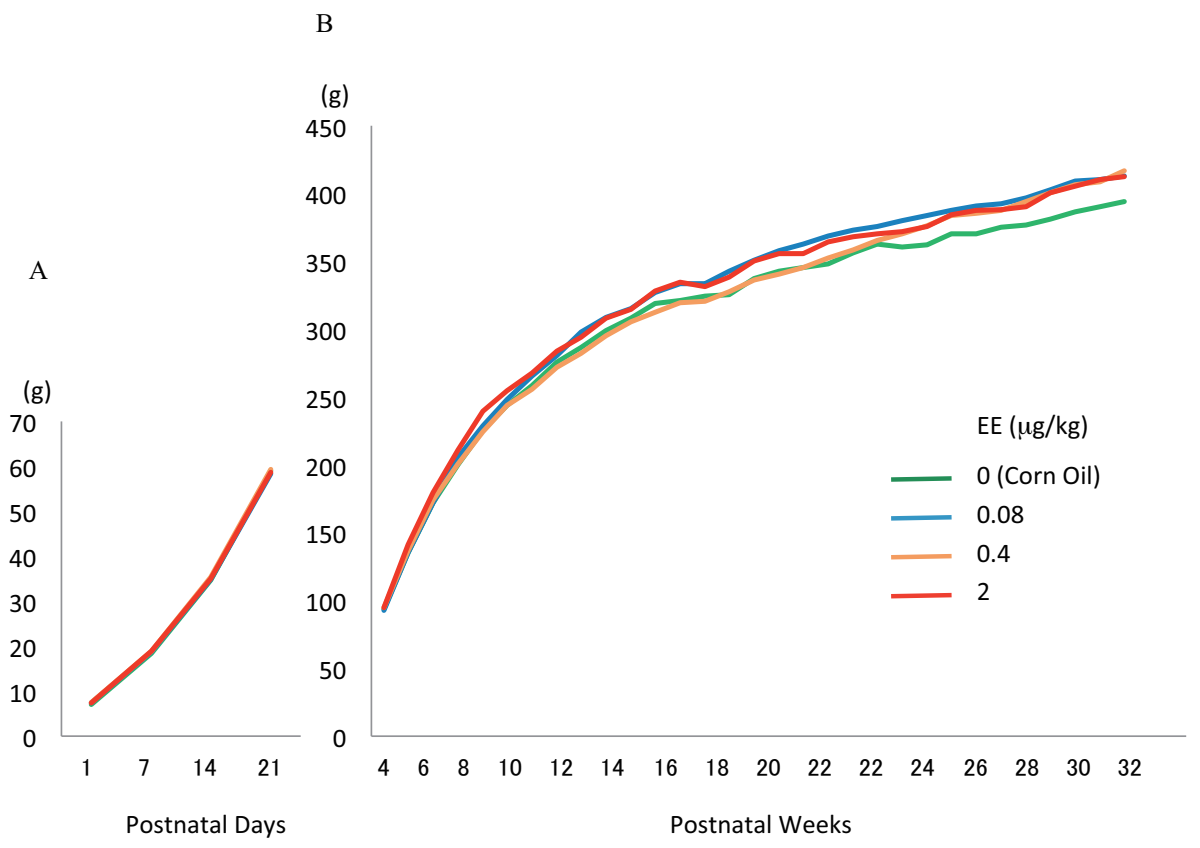

Fig. 1. Body weight changes of animals during the pre- (A) and post- (B) weaning periods. The animals were administered $0,0.08$, 0.4 or $2 \mu \mathrm{g} / \mathrm{kg}$ of $17 \alpha$-ethynylestradiol (EE) subcutaneously on postnatal day1. $\mathrm{N}=11$ until postnatal week 4 , and $\mathrm{N}=8-9$ from postnatal week 5 to 34 . 


\section{Shiorta et al.}

Table 1. Effects of neonatal $17 \alpha$-ethynylestradiol (EE) exposure on the body weight (BW), age at eye opening, and age at vaginal opening of female rats subcutaneously treated with EE on postnatal day 1.

\begin{tabular}{lcccc}
\hline Dose of EE $(\mu \mathrm{g} / \mathrm{kg})$ & 0 & 0.08 & 0.4 & 2 \\
\hline Number of animals examined & 11 & 10 & 11 & 11 \\
\hline Age at eyes opening (day) & $13.8 \pm 0.1$ & $13.9 \pm 0.2$ & $13.7 \pm 0.1$ & $13.6 \pm 0.1$ \\
BW at eyes opening (g) & $35.1 \pm 0.9$ & $34.8 \pm 0.9$ & $35.4 \pm 0.9$ & $35.0 \pm 0.9$ \\
Age at vaginal opening (day) & $32.1 \pm 0.5$ & $33.0 \pm 0.5$ & $32.2 \pm 0.5$ & $32.5 \pm 0.5$ \\
BW at vaginal opening $(\mathrm{g})$ & $115 \pm 3$ & $120 \pm 3$ & $118 \pm 3$ & $121 \pm 3$ \\
\hline
\end{tabular}

Values represent mean \pm standard error of the mean (S.E.M).

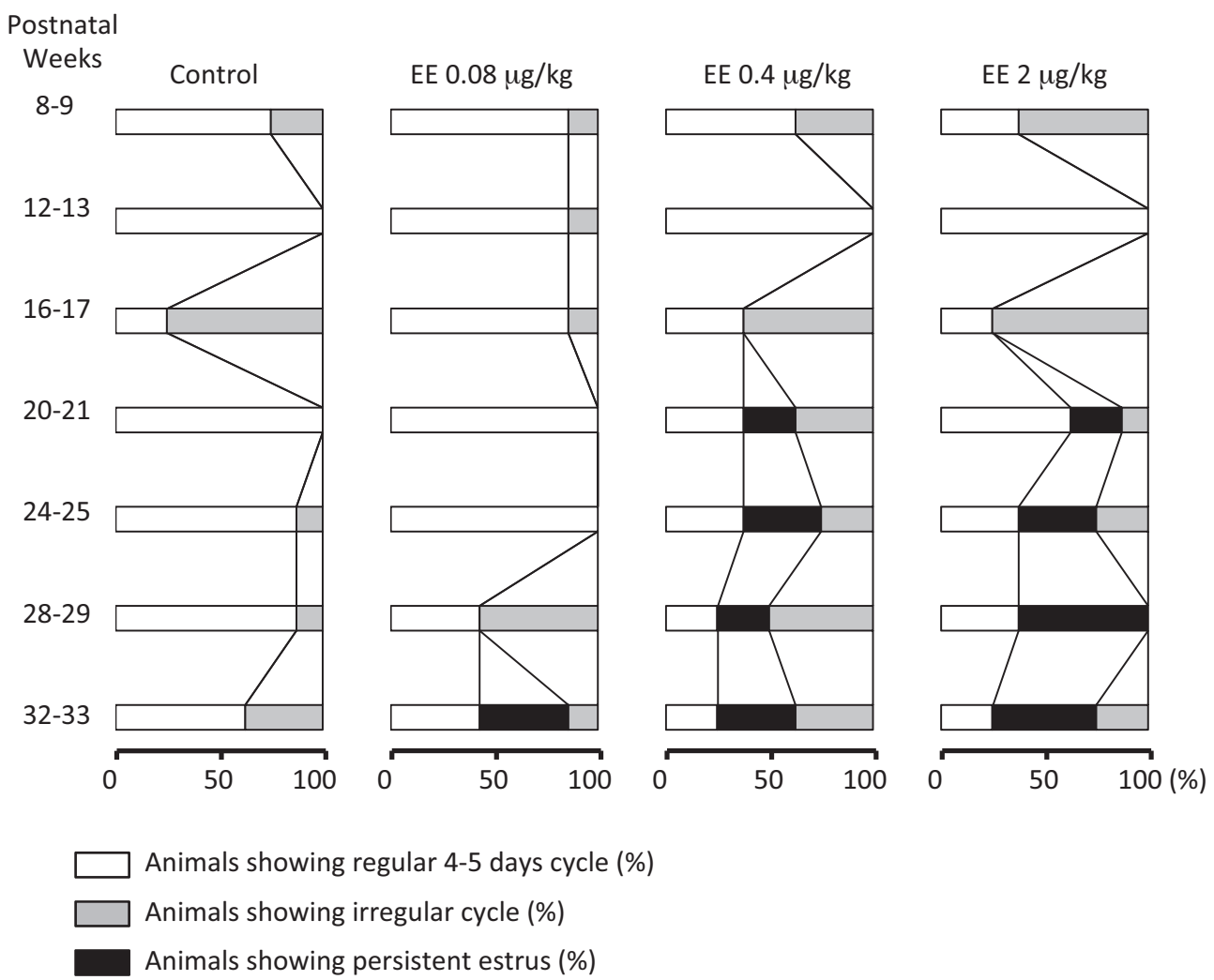

Fig. 2. Proportions of animals with regular (4-5 days) cycle, irregular cycle or persistent estrus during each observation period. EE, $17 \alpha$-ethynylestradiol.

ent compared with those in the control group until PNW 17 , whereas the number of estrous cycles occurring during PNW 12-13 in the $2 \mu \mathrm{g} / \mathrm{kg}$ EE-treated group was significantly smaller than that in the control group (Table 2) because of normal but slightly longer intervals of the estrous cycle (mean \pm S.E.M. was 4.4 days \pm 0.1 in the $2 \mu \mathrm{g} / \mathrm{kg}$ EE-treated group and 4.0 days \pm 0.1 in the control group); however, from PNW 20-21, the animals in the $0.4 \mu \mathrm{g} / \mathrm{kg}$ or more EE-treated groups began to show per- sistent estrus (Fig. 2), and the number of estrous cycles occurring during PNW 20-21 in the $2 \mu \mathrm{g} / \mathrm{kg}$ EE-treated group was significantly lesser than that in the control group (Table 2). In addition, the number of estrous/ proestrous days became significantly greater from PNW 24-25 in the $2 \mu \mathrm{g} / \mathrm{kg}$ EE-treated group and PNW 28-29 in the $0.4 \mu \mathrm{g} / \mathrm{kg}$ EE-treated group compared with that in the control group (Table 2, Fig. 3). Furthermore, the animals in the $0.08 \mu \mathrm{g} / \mathrm{kg}$ EE-treated group began to show persist- 
Delayed effects of single neonatal injection of $17 \alpha$-ethynylestradiol

Table 2. Effects of neonatal $17 \alpha$-ethynylestradiol (EE) exposure on the number of estrous cycle revolved and the number of estrous/proestrous days for each observation period in the female rats subcutaneously treated with EE on postnatal day 1.

\begin{tabular}{ccccc}
\hline Dose of EE $(\mu \mathrm{g} / \mathrm{kg})$ & 0 & 0.08 & 0.4 & 2 \\
\hline $\begin{array}{c}\text { Number of animals examined } \\
\text { Observation period (postnatal week) }\end{array}$ & 8 & 7 & The number of estrous cycle revolved & 8 \\
$8-9$ & $1.9 \pm 0.2$ & $1.0 \pm 0.2$ & $1.5 \pm 0.2$ & $1.6 \pm 0.2$ \\
$12-13$ & $2.4 \pm 0.2$ & $2.4 \pm 0.2$ & $2.3 \pm 0.2$ & $1.8 \pm 0.2^{*}$ \\
$16-17$ & $1.6 \pm 0.2$ & $2.0 \pm 0.3$ & $1.3 \pm 0.2$ & $1.4 \pm 0.2$ \\
$20-21$ & $2.1 \pm 0.3$ & $2.4 \pm 0.3$ & $1.6 \pm 0.3$ & $1.1 \pm 0.3^{*}$ \\
$24-25$ & $2.0 \pm 0.3$ & $2.3 \pm 0.3$ & $1.5 \pm 0.3$ & $1.3 \pm 0.3$ \\
$28-29$ & $1.8 \pm 0.3$ & $1.4 \pm 0.4$ & $1.3 \pm 0.3$ & $1.1 \pm 0.3$ \\
$32-33$ & $1.6 \pm 0.3$ & $1.4 \pm 0.4$ & $0.8 \pm 0.3$ & $0.8 \pm 0.3$ \\
\hline-9 & & The number of estrous/proestrous days & \\
$12-13$ & $5.0 \pm 0.5$ & $5.9 \pm 0.6$ & $5.5 \pm 0.5$ & $5.3 \pm 0.5$ \\
$16-17$ & $6.0 \pm 0.5$ & $5.6 \pm 0.6$ & $6.0 \pm 0.5$ & $5.0 \pm 0.5$ \\
$20-21$ & $6.0 \pm 0.8$ & $5.0 \pm 0.8$ & $6.0 \pm 0.8$ & $6.3 \pm 0.8$ \\
$24-25$ & $4.5 \pm 1.1$ & $5.7 \pm 1.2$ & $7.0 \pm 1.1$ & $8.1 \pm 1.1$ \\
$28-29$ & $4.5 \pm 1.0$ & $5.4 \pm 1.1$ & $8.1 \pm 1.0$ & $9.3 \pm 1.0^{* *}$ \\
$32-33$ & $3.9 \pm 1.2$ & $7.0 \pm 1.2$ & $9.4 \pm 1.2^{* *}$ & $9.8 \pm 1.2^{* *}$ \\
\hline
\end{tabular}

Values represent mean \pm standard error of the mean (S.E.M.).

$*$ and $* *$, significantly different from control at $p<0.05$ and 0.01 respectively.

ent estrus at PNW 32-33; however, significant differences were not observed in any parameter. Thus, the estrous cycle in the EE-treated groups had a marked tendency to lose cyclic revolution, and the animals had longer proestrus or estrus days.

\section{Effects of EE on ovulation, organ weight, and macro- and histopathology}

Subcutaneous spots or macular milk accumulations were macroscopically identified at necropsy in $0 / 8,1 / 7$, $4 / 8$, and $3 / 8$ animals in the $0,0.08,0.4$ and $2 \mu \mathrm{g} / \mathrm{kg} \mathrm{EE}-$ treated groups, respectively (Fig. 4A). Microscopical examination revealed these lesions in the $2 \mu \mathrm{g} / \mathrm{kg}$ EEtreated groups, and acinar cell hyperplasia with milk secretion and dilated ducts were found in the mammary gland (Fig. 4B); however any proliferating lesion including anterior adenoma or focal hyperplasia was not detected in the pituitary of the animals with mammary gland hyperplasia (data not shown).

There were no significant differences in the weights of non-reproductive organs between the control and EEtreated groups, although EE-treated animals may have slightly larger pituitary and adrenal glands (Table 3). The weights of ovaries and uteri were analyzed based on whether or not the animals had ovulated at the time of necropsy (Table 4). Except for one animal showing persistent estrus, all the control animals observed at estrus were confirmed to have ovulated and had shed a normal number of oocytes. Because only one animal in the 0.08 and $2 \mu \mathrm{g} / \mathrm{kg}$ EE-treated groups had ovulated, we only compared the weights of ovaries and uteri of the EE-treated animals with those of the unovulated control animals and found no significant differences in the organ weight. Corpus luteum was observed in approximately half of the EE-treated animals (Table 5); however, the majority contained cystic follicles (Fig. 5, Table 5). Among the animals lacking corpus luteum, two and one animals in the 0.4 and $2 \mu \mathrm{g} / \mathrm{kg}$ EE-treated groups, respectively, showed irregular estrous cycle until necropsy, whereas the others showed persistent estrus.

\section{DISCUSSION}

The perinatal period is critical for brain sexual dif- 

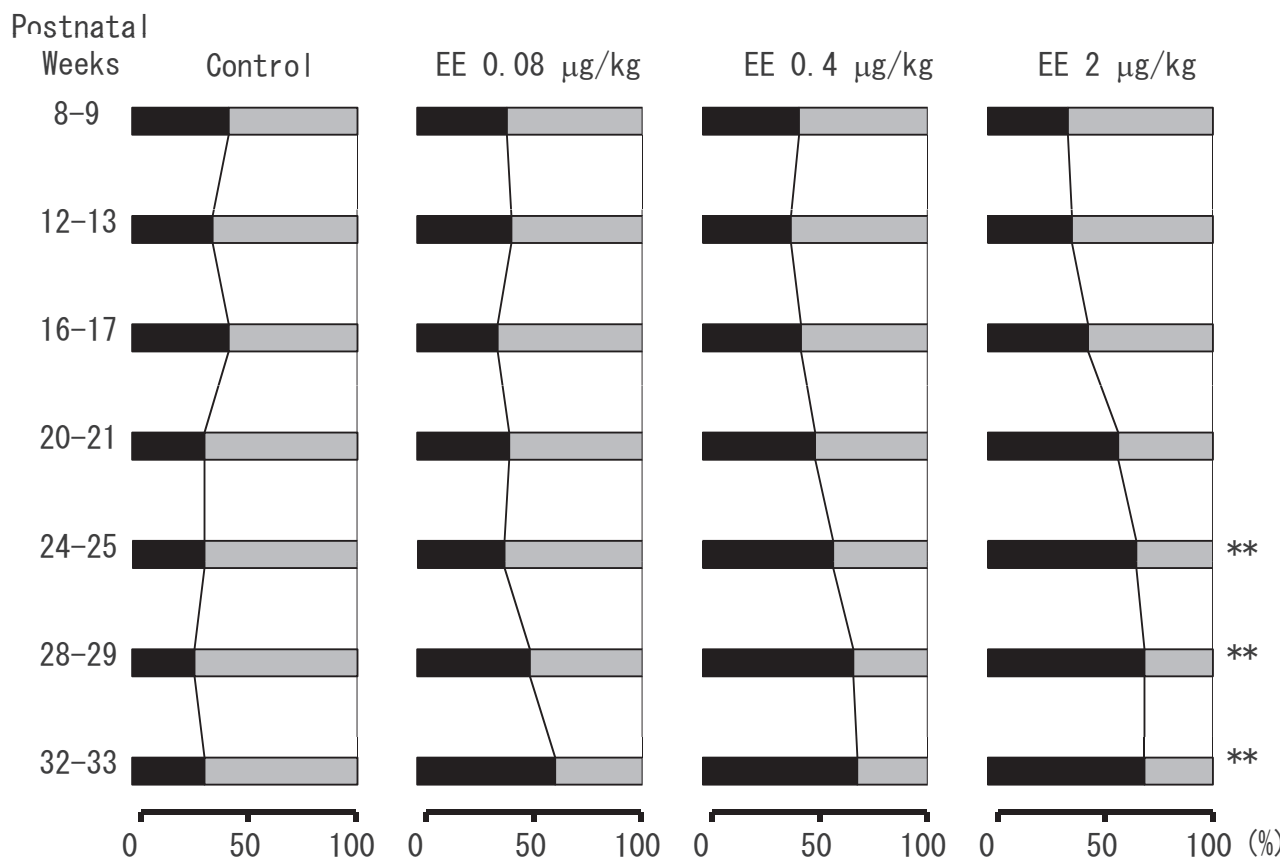

Estrous/proestrous days (\%)

Diestrous/metestrous days (\%)

** Significantly different in the estrous/proestrous days compared with those in the control at $p<0.01$

Fig. 3. Proportions of days judged as estrus or proestrus (estrous/proestrous days) and those judged as diestrus or metestrus (diestrous/metestrus days) during each observation period. EE, 17 $\alpha$-ethynylestradiol

Table 3. Effects of neonatal 17a-ethynylestradiol (EE) exposure on weights of non-reproductive organs collected from female rats subcutaneously treated with EE on postnatal day 1.

\begin{tabular}{|c|c|c|c|c|}
\hline Dose of EE $(\mu \mathrm{g} / \mathrm{kg})$ & 0 & 0.08 & 0.4 & 2 \\
\hline Number of animals examined & 8 & 7 & 8 & 8 \\
\hline BW at necropsy (g) & $395 \pm 19$ & $399 \pm 20$ & $422 \pm 19$ & $414 \pm 19$ \\
\hline Pituitary & $19 \pm 2$ & $22 \pm 2$ & $26 \pm 2$ & $24 \pm 2$ \\
\hline Thymus (mg) & $148 \pm 13$ & $145 \pm 14$ & $133 \pm 13$ & $161 \pm 13$ \\
\hline Liver (g) & $11.9 \pm 0.6$ & $12.1 \pm 0.7$ & $13.2 \pm 0.6$ & $12.7 \pm 0.6$ \\
\hline Kidneys (g) & $2.2 \pm 0.1$ & $2.2 \pm 0.1$ & $2.3 \pm 0.1$ & $2.4 \pm 0.1$ \\
\hline Spleen (mg) & $611 \pm 27$ & $636 \pm 29$ & $633 \pm 27$ & $641 \pm 27$ \\
\hline Adrenal glands (mg) & $72 \pm 4$ & $80 \pm 5$ & $82 \pm 4$ & $84 \pm 4$ \\
\hline
\end{tabular}

Values represent mean \pm standard error of the mean (S.E.M.).

ferentiation in rodents and is highly sensitive to aromatizable testosterone or estrogenic compounds, including synthetic estrogens, xenoestrogens, and phytoestrogens. Aromatized estrogenic compounds inappropriately masculinize the brain in female neonates and lose cyclic rev- olution of estrus after puberty (reviewed in Gore, 2008). In the present study, we have shown that neonatal exposure to EE interfered with the estrous cycle, by decreasing the number of estrous cycle revolved and causing persistent estrus, whereas untreated animals had normal 
A

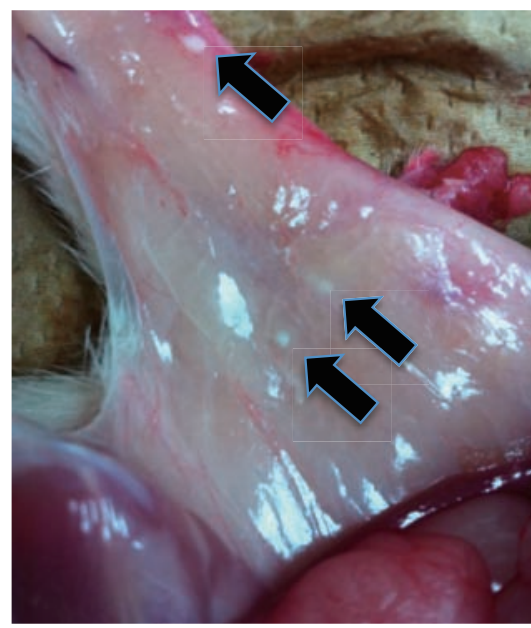

B

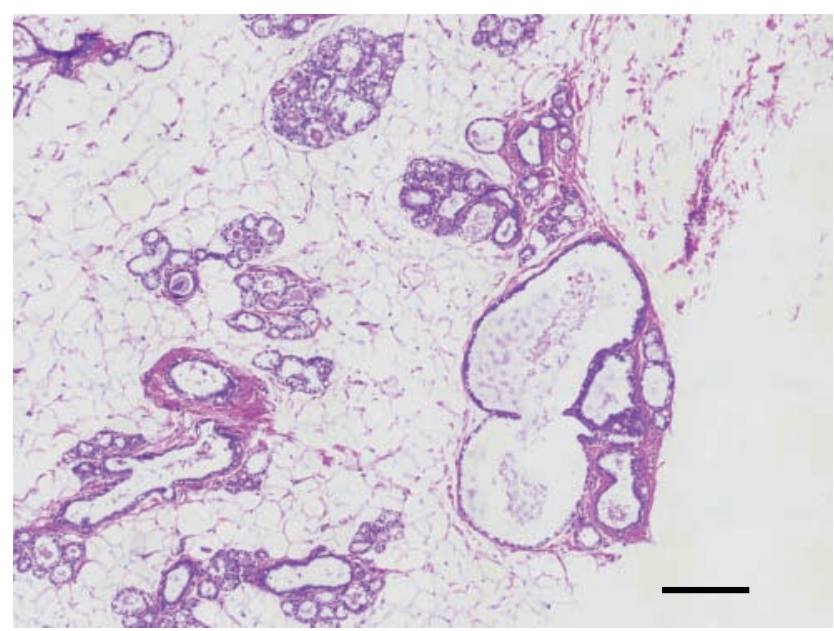

Fig. 4. A representative photograph found macular accumulations of milky solution (arrows in A), and a histopathological appearance of the mammary gland (B) collected at the terminal necropsy from female rats exposed to $2 \mu \mathrm{g} / \mathrm{kg}$ of $17 \alpha$-ethynylestradiol on postnatal day 1 . Note acinar cell hyperplasia with milk secretion and duct dilatation in the mammary tissue. $($ Bar $=200 \mu \mathrm{m})$.

A

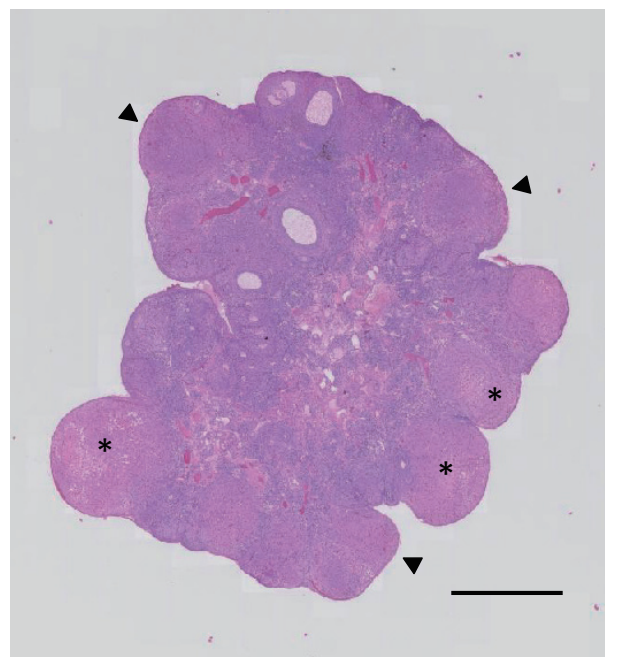

B



Fig. 5. Histological appearance of the ovaries collected at the terminal necropsy from female rats exposed to 0 (A) or $2 \mu \mathrm{g} / \mathrm{kg}$ of $17 \alpha$-ethynylestradiol (B) on postnatal day 1 . Note that there are newly formed (arrowheads) and morphologically regressing corpora lutea (asterisks) in the control ovary (A). In the 17 1 -ethynylestradiol -treated ovary, there are large cystic or atretic follicles but no corpus luteum $(B)$. (Bars $=1 \mathrm{~mm})$.

4-5 day estrous cycles. Thus, single neonatal exposure to $0.4 \mu \mathrm{g} / \mathrm{kg}$ EE had adverse effects more than 20 weeks later, highlighting the vulnerability of brain sexual differentiation to exogenous estrogenic compounds during this critical period (Morris et al., 2004; Gore, 2008).
This effect was also dose-dependent, occurring the earliest in the animals treated with the highest dose, although the Sprague-Dawley rat strain is known to develop persistent vaginal cornification with age (vom Saal et al., 1994). Some animals in the $0.08 \mu \mathrm{g} / \mathrm{kg}$ EE-treated group 
Table 4. Weights of reproductive organs from female rats treated with 17 $\alpha$-ethynylestradiol (EE) subcutaneously on postnatal day 1.

\begin{tabular}{lcccc}
\hline Dose of EE $(\mu \mathrm{g} / \mathrm{kg})$ & 0 & 0.08 & 0.4 & 2 \\
\hline Animals examined & 8 & 7 & 8 & 8 \\
Animals on the day of estrus ${ }^{\mathrm{a}}$ & 6 & 7 & 8 & 8 \\
Animals found ovulating & 5 & 1 & 0 & 1 \\
$\quad$ Body weight $(\mathrm{g})$ & $377 \pm 21$ & 409 & & 453 \\
Number of oocytes shed & $13.2 \pm 1.2$ & 1 & & 13 \\
Ovaries (mg) & $94 \pm 6$ & 113 & & 636 \\
Uterus (mg) & $630 \pm 37$ & 614 & & 1 \\
Presence of cystic follicles & 0 & 0 & 8 & 7 \\
Animals not ovulating & 3 & 6 & $422 \pm 21$ & $411 \pm 24$ \\
Body weight (g) & $425 \pm 34$ & $397 \pm 24$ & $61 \pm 6$ & $61 \pm 7$ \\
Ovaries (mg) & $82 \pm 10$ & $59 \pm 7$ & $664 \pm 47$ & $700 \pm 54$ \\
Uterus (mg) & $606 \pm 77$ & $780 \pm 54$ & & \\
\hline
\end{tabular}

Values represent mean \pm standard error of the mean (S.E.M.).

ancluding animals showing persistent estrus.

Table 5. Histological evaluation of ovaries collected at terminal necropsy from female rats subcutaneously treated with $17 \alpha$-ethynylestradiol (EE) on postnatal day 1.

\begin{tabular}{llccc}
\hline Dose of EE $(\mu \mathrm{g} / \mathrm{kg})$ & 0 & 0.08 & 0.4 & 2 \\
\hline Animals examined & 8 & 7 & 8 & 8 \\
Absence of corpus luteum & 1 & 3 & 5 & 4 \\
Presence of cystic follicles & 2 & 5 & 5 & 7 \\
\hline
\end{tabular}

began to show persistent estrus at PNW 32-33; however, no statistical differences were observed. Considering the dose-related increase in the frequency of persistent estrus in the $0.4 \mu \mathrm{g} / \mathrm{kg}$ or more EE-treated group, occurrence of the persistent estrus in the $0.08 \mu \mathrm{g} / \mathrm{kg}$ treated group might reflect both effects of neonatal EE treatment and spontaneous aging. Thus, such effects of a lower dose of estrogenic compounds could be hidden by aging.

Although EE is a common synthetic estrogen used for various medical purposes, its effects on female reproductive development have been studied only by administration to pregnant or lactating dams (Tinwell et al., 2002; Fusani et al., 2007; Ryan et al., 2010). Oral treatment of pregnant dams during gestational days 6-21 accelerated vaginal opening of their offspring and increased period in the estrus at a dose level of $20 \mu \mathrm{g} / \mathrm{kg} /$ day (Tinwell et al., 2002). Similarly, oral treatment of pregnant and lactating dams with $5 \mu \mathrm{g} / \mathrm{kg} /$ day EE from gestational day 7 to PND 18 has been reported to cause abnormalities such as development of cleft phallus, acceleration of vaginal opening and reduction of fecundity (Ryan et al., 2010). In contrast, $0.4 \mathrm{ng} / \mathrm{kg} /$ day of EE did not have any effect on reproductive development of female offspring from dams orally treated with EE from gestational day 15 to PND 21 (Fusani et al., 2007). Except this dose level, transgenerational administration with various doses of EE seems to affect the estrous cycle; however, the present study revealed that single subcutaneous injection with at least $0.08 \mu \mathrm{g} / \mathrm{kg}$ of EE to pups at PND 1 affects estrous cycle at a later period.

Because in vivo administration with estrogenic compounds is able to increase uterine weight of ovariectomized or immature intact female rats or mice, the "rat uterotropic bioassay", has been established for evaluation of estrogenic potency of chemical substances in vivo (Kanno et al., 2001). In the phase I validation study for the bioassay (Kanno, et al., 2001), where the immature and adult ovariectomized rat uterotrophic assays were performed in 19 laboratories with a reference agonist of estrogen receptors, EE, the lowest observed effect level 
Delayed effects of single neonatal injection of $17 \alpha$-ethynylestradiol

(LOEL) of EE required to increase the uterine weight in immature and ovariectomized adult rats was reported to be $0.03-0.3$ and $0.1-1.0 \mu \mathrm{g} / \mathrm{kg} / \mathrm{day}$, respectively, for three days by subcutaneous injection. The lowest dose applied in the present single injection study is similar to or lower than these levels. Based on our data, we conclude that the estrous cycle is one of sensitive biomarkers to evaluate delayed effects of neonatal exposure to estrogenic compounds.

In the present study, the lowest dose of EE took the longest time to cause persistent estrus, suggesting the possible involvement of a dose-dependent mechanism in acceleration of reproductive senescence. Exposure of neonatal female rats to $0.1-100 \mu \mathrm{g}$ of estradiol benzoate (EB) led to a dose-dependent decrease in hypothalamic Kiss 1 mRNA levels during the prepubertal period (Navarro et al., 2009). Kiss 1 encodes a family of kisspeptin neuropeptides, which are critical upstream regulators of gonadotropin-releasing hormone $(\mathrm{GnRH})$ secretion. Kisspeptin signaling is essential for the onset of puberty and control of preovulatory gonadotropin surges (Adachi et al., 2007; Tena-Sempere, 2010; Roa et al., 2011). Perinatal exposure to various estrogenic compounds, including genestein (Losa et al., 2011) and bisphenol-A (Patisaul et al., 2009), disrupt the kisspeptin system in the anteroventral periventricular nucleus (AVPN), where the GnRH surge is generated. Furthermore, exposure of the hypothalamus of adult female rats to $1 \mathrm{mg}$ of $\mathrm{EB}$ or $10 \mu \mathrm{g}$ or $100 \mathrm{mg}$ of methoxychlor during the prenatal and postnatal periods caused up-regulation of Kiss 1 and down-regulation of estrogen receptor $\alpha(E s r l)$ in the preoptic area and also caused extensive methylation of the Esr 1 promoter (Gore et al., 2011). Based on these findings, similar dose-dependent alterations might also occur following single exposure to low-dose EE used in our study, average: $0.59-14 \mathrm{ng}$.

In addition to reproductive senescence, leakage of milk from the mammary gland was frequently observed in the EE-treated animals. Because hyperplasia of the mammary gland was histologically evident, milk production is likely to be enhanced in nulliparous rats in the present study. While the milk was found in most animals showing persistent estrus, mammary hyperplasia was not always explained by the endocrinological imbalance caused by reproductive senescence. There is abundant evidence that neonatal exposure to estrogenic compounds such as diethylstilbestrol (Umekita et al., 2011), BPA (Betancourt et al., 2010; Ayyanan et al, 2011), and butyl benzyl phthalate (Moral et al., 2011) can directly cause morphological or molecular alterations in the mammary gland. Detailed examination, including quantification and analysis of methylation for genes encoding such molecules, may help to understand the causes of milk production in nulliparous female rats.

In the present study, we observed no discernible effect of EE exposure on the timing of vaginal opening. There are conflicting reports on the effect of perinatal exposure to estrogenic compounds on the timing of vaginal opening. Perinatal exposure to butyl benzyl phthalate (Moral et al., 2011) or p-octylphenol (Nagao et al., 2001) modify the timing of vaginal opening, whereas neonatal exposure to bisphenol A, nonylphenol or genistein have a negative effect on the timing of vaginal opening (Noda et al., 2005).

Although ovulation was detected in all the control animals examined on the day of estrus, the majority of EEtreated animals, even those with an irregular estrous cycle, had not ovulated. Furthermore, several animals in the EE-treated groups and one in the control group lacked corpus luteum. In the ovaries of cycling rats, there are different generations of corpora lutea, because several estrous cycles are required for complete elimination of corpora lutea by structural regression. Therefore, the animals lacking corpus luteum are judged to be anovulatory in the long term.

In conclusion, single exposure to low-dose EE during the critical period of brain sexual differentiation causes delayed effects on the estrous cycle and the mammary gland, and these effects could be hidden by spontaneous aging in rats.

\section{ACKNOWLEDGMENTS}

We gratefully thank Dr. Miwako Kamiie and Dr. Yoko Kakinuma for their assistance in continuing this study. This study was partly supported by a grant-in-aid for research on risk of the origin of chemical compounds from the Minister of Health, Labor and Welfare (H22Kagaku-Ippan-003).

\section{REFERENCES}

Adachi, S., Yamada, S., Takatsu, Y., Matsui, H., Kinoshita, M., Takase, K., Sugiura, H., Ohtaki, T., Matsumoto, H., Uenoyama, Y., Tsukamura, H., Inoue, K. and Maeda, K.I. (2007): Involvement of anteroventral periventricular metastin/kisspeptin neurons in estrogen positive feedback action on luteinizing hormone release in female rats. J. Reprod. Dev., 53, 367-378.

Adewale, H.B., Jefferson, W.N., Newbold, R.R. and Patisaul, H.B. (2009): Neonatal bisphenol-A exposure alters rat reproductive development and ovarian morphology without impairing activation of gonadotropin-releasing hormone neurons. Biol. Reprod., 81, 690-699.

Armenti, A.E., Zama, A.M., Passantino, L. and Uzumcu, M. (2008): 
Developmental methoxychlor exposure affects multiple reproductive parameters and ovarian folliculogenesis and gene expression in adult rats. Toxicol. Appl. Pharmacol., 233, 286-296.

Ayyanan, A., Laribi, O., Schuepbach-Mallepell, S., Schrick, C., Gutierrez, M., Tanos, T., Lefebvre, G., Rougemont, J., YalcinOzuysal, O. and Brisken, C. (2011): Perinatal exposure to bisphenol A increases adult mammary gland progesterone response and cell number. Mol. Endocrinol., 25, 1915-1923.

Betancourt, A.M., Eltoum, I.A., Desmond, R.A., Russo, J. and Lamartiniere, C.A. (2010): In utero exposure to bisphenol A shifts the window of susceptibility for mammary carcinogenesis in the rat. Environ. Health Perspect., 118, 1614-1619.

Burdick, H.O. and Whitney, R. (1941): Ovulation induced in mice by single injections of follutein or untreated human pregnancy urine. Am. J. Physiol., 132, 405-410.

Fusani, L., Seta, D.D., Dessi-Fulgheri, F. and Farabollin, F. (2007): Altered reproductive success in rat pairs after environmental-like exposure to xenoestrogen. Proc. Biol. Sci., 274, 1631-1636.

García-Galliano, D., Pinilla, L. and Tena-Sempere, M. (2012): Sex steroids and the control of the kiss1 system: developmental roles and major regulatory actions. J. Neuroendocrinol., 24, 22-33.

Gellert, R.J., Heinrichs, W.L. and Swerdloff, R. (1974) Effects of neonatally-administered DDT homologs on reproductive function in male and female rats. Neuroendocrinology, 16, 84-94.

Gore, A.C. (2008): Developmental programming and endocrine disruptor effects on reproductive neuroendocrine systems. Front. Neuroendocrinol., 29, 358-374.

Gore, A.C., Walker, D.M., Zama, Q.M., Armenti, A.M.E. and Uzumcu, M. (2011): Early life exposure to endocrine-disrupting chemicals causes lifelong molecular reprogramming of the hypothalamus and premature reproductive aging. Mol. Endocrinol., 25, 2157-2168.

Kanno, J., Onyon, L., Haseman, J., Fenner-Crisp, P., Ashby, J. and Owens, W. (2001): The OECD program to validate the rat uterotrophic bioassay to screen compounds for in vivo estrogenic responses: Phase 1. Environ. Health Perspect., 109, 785-794.

Kanno, J., Onyon, L., Peddada, S., Ashby, J., Jacob, E. and Owens, W. (2003): The OECD program to validate the rat uterotrophic bioassay. Phase 2: Coded single-dose studies. Environ. Health Perspect., 111, 1550-1558.

Kim, H.S., Kang, T.S., Kang, I.H., Kim, T.S., Moon, H.J., Kim, I.Y., Ki, H., Park, K.L., Lee, B.M., Yoo, S.D. and Han, S.Y. (2005): Validation study of OECD rodent uterotrophic assay for the assessment of estrogenic activity in Sprague-Dawley immature female rats. J. Toxicol. Environ. Health A, 68, 2249-2262.

Losa, S.M., Todd, K.L., Sullivan, A.W., Cao, J., Mickens, J.A. and Patisaul, H.B. (2011): Neonatal exposure to genistein adversely impacts the ontogeny of hypothalamic kisspeptin signaling pathways and ovarian development in the peripubertal female rat. Reprod. Toxicol., 31, 280-289.

Monje, L., Varayoud, J., Mũnoz-de-Toro, M., Luque, E.H. and Ramos, J.G. (2010): Exposure of neonatal female rats to bisphenol A disrupts hypothalamic LHRH pre-mRNA processing and estrogen receptor alpha expression in nuclei controlling estrous cyclicity. Reprod. Toxicol., 30, 625-634.

Moral, R., Santucci-Pereira, J., Wang, R., Russo, I.H., Lamartiniere,
C.A. and Russo, J. (2011): In utero exposure to butyl benzyl phthalate induces modifications in the morphology and the gene expression profile of the mammary gland: an experimental study in rats. Environ. Health, 10, 5.

Morris, J.A., Cynthia, L., Jordan, C.L. and Breedlove, S.M. (2004): Sexual differentiation of the vertebrate nervous system. Nat. Neurosci., 7, 1034-1039.

Nagao, T., Yoshimura, S., Saito, Y., Nakagomi, M., Usumi, K. and Ono, H. (2001): Reproductive effects in male and female rats from neonatal exposure to $p$-octylphenol. Reprod. Toxicol., 15, 683-692.

Navarro, V.M., Sánchez-Garrido, M.A., Castellano, J.M., Roa, J., García-Galiano, D., Pineda, R., Aguilar, E., Pinilla, L. and Tena-Sempere, M. (2009): Persistent impairment of hypothalamic KiSS-1 system after exposures to estrogenic compounds at critical periods of brain sex differentiation. Endocrinology, 150, 2359-2367.

Noda, S., Muroi, T., Mitomai, H., Takakura, S., Sakamoto, S., Minobe, A. and Yamasaki, K. (2005): Reproductive toxicity study of bisphenol A, nonylphenol, and genistein in neonatally exposed rats. Toxicol. Pathol., 18, 203-207.

Owens, W. and Koëter, H.B.W.M. (2003): The OECD Program to validate the rat uterotrophic bioassay: An overview. Environ. Health Perspect., 111, 1527-1529.

Patisaul, H.B., Todd, K.L., Mickens, J.A. and Adewale, H.B. (2009): Impact of neonatal exposure to the ER $\alpha$ agonist PPT, bisphenolA or phytoestrogens on hypothalamic kisspeptin fiber density in male and female rats. Neurotoxicology, 30, 350-357.

Roa, J., Navarro, V.M. and Tena-Sempere, M. (2011): Kisspeptins in reproductive biology: Consensus knowledge and recent developments. Biol. Reprod., 85, 650-660.

Ryan, B.C., Hotchkiss, A.R., Crofton, K.M. and Gray, L.E.Jr. (2010): In utero and lactational exposure to bisphenol A, in contrast to ethinyl estradiol, does not alter sexually dimorphic behavior, puberty, fertility, and anatomy of female LE rats. Toxicol. Sci., 114, 133-148.

vom Saal, F.S., Finch, C.E. and Nelson, J. F. (1994): Natural history and mechanisms of reproductive aging in humans, laboratory rodents, and other selected vertebrates. In Physiology of Reproduction, second ed. (Knobil, E. and Neil, J.D. eds.), volume 2, pp.1213-1314, Raven Press, New York.

Tena-Sempere, M. (2010): Kisspeptin/GPR54 system as potential target for endocrine disruption of reproductive development and function. Int. J. Androl., 33, 360-368.

Tinwell, H., Haseman, J., Lefevre, P.A., Wallis, N. and Ashby, J. (2002): Normal sexual development of two strains of rat exposed in utero to low doses of bisphenol A. Toxicol. Sci., 68, 339-348.

Umekita, Y., Souda, M., Hatanaka, K., Hamada, T., Yoshioka, T., Kawaguchi, H. and Tanimoto, A. (2011): Gene expression profile of terminal end buds in rat mammary glands exposed to diethylstilbestrol in neonatal period. Toxicol. Lett., 205, 15-25.

Vandenberg, L.N., Maffini, M.V., Sonnenschein, C., Rubin. B.S. and Soto, A.M. (2009): Bisphenol-A and the great divide: a review of controversies in the field of endocrine disruption. Endocr. Rev., 30, 75-95. 